\title{
ACTIVITIES OF ASIAN STUDENTS AND YOUNG SCIENTISTS ON PHOTOGRAMMETRY AND REMOTE SENSING
}

\author{
Hiroyuki Miyazaki ${ }^{\mathrm{a}, *}$ Chao-Yuan Lo ${ }^{\mathrm{b}}$, Kohei Cho $^{\mathrm{c}}$ \\ ${ }^{a}$ Center for Spatial Information Science, The University of Tokyo, Japan - heromiya@csis.u-tokyo.ac.jp \\ ${ }^{\mathrm{b}}$ Center for Space and Remote Sensing Research, National Central University, Taiwan - freezer@csrsr.ncu.edu.tw \\ ${ }^{\mathrm{c}}$ Research \& Information Center, Tokai University, Japan - cho@yoyogi.ycc.u-tokai.ac.jp
}

Commission VI, WG VI/5

\begin{abstract}
KEY WORDS: student activities, Asian Association on Remote Sensing (AARS), Asian Conference on Remote Sensing (ACRS), Student Chapter
\end{abstract}

\begin{abstract}
:
This paper reports a history and future prospects of the activities by Asian students and young scientists on photogrammetry and remote sensing. For future growths of academic fields, active communications among students and young scientists are indispensable. In some countries and regions in Asia, local communities are already established by youths and playing important roles of building networks among various schools and institutes. The networks are expected to evolve innovative cooperations after the youths achieve their professions. Although local communities are getting solid growth, Asian youths had had little opportunities to make contacts with youths of other countries and regions. To promote youth activities among Asian regions, in 2007, Asian Association on Remote Sensing (AARS) started a series of programs involving students and young scientists within the annual conferences, the Asian Conference on Remote Sensing (ACRS). The programs have provided opportunities and motivations to create networks among students and young scientists. As a result of the achievements, the number of youth interested and involved in the programs is on growing. In addition, through the events held in Asian region by ISPRS Student Consortium (ISPRS-SC) and WG VI/5, the Asian youths have built friendly partnership with ISPRS-SC. Currently, many Asian youth are keeping contacts with ACRS friends via internet even when they are away from ACRS. To keep and expand the network, they are planning to establish an Asian youth organization on remote sensing. This paper describes about the proposals and future prospects on the Asian youth organization.
\end{abstract}

\section{INTRODUCTION}

In a long history of photogrammetry and remote sensing, many students learned the technologies and applications. They have deployed knowledge learned at their school to industries and government following to their graduations from schools. It indicates that students are possibly to be medium among academia, industry, and government. For contribution of academia to public society, stakeholders need to exchange ideas among disciplines over through basic technologies to applications. To be good medium, students majoring basic technologies should learn applications and students majoring application fields should learn basic technologies as broad as possible. Schools often have programs and lectures aligning basic technologies and applications to promote understanding the connectivity. However, contents of programs and lectures are quite limited due to time and dependency on lecturers.

In some academic fields, to overcome the limitation, youth activities of academic exchange are actively promoted by academic organization and youth volunteers. Students have plenty time to develop much more channels than professorstudent communication has. It is expected to create unexpected opportunities of exchanging new knowledge required for innovative progress.

For such academic exchange to be effective, networking among students is definitively required. For students, especially in developing countries, frequent meeting and mailing is impossible due to financial reasons. Recently, every school and institute of the world provides Internet accesses to students. Owing to even accessibility of students to the Internet, students can easily maintain their relationships with foreign students who have shared interests and knowledge at international conferences. In addition, they can keep contacts using permanent e-mail address and social networking services (SNS). Such opportunities of students have chances to be grown into innovative contribution to the world when they take up practical positions in society.

In addition to students, young scientists also have important roles in bridging academia and public society as informal mentors for students. Asian Association on Remote Sensing (AARS) has been attempting to promote such experiences of students and young scientist in Asia. In this paper, we review existing student's activities $\mathrm{n}$ academic fields, describe a history of student's activities of AARS and conclude with proposals and future prospects of AARS Student Group.

\section{HISTORY OF ASIAN STUDENTS ACTIVITIES}

The history of Asian student activities of photogrammetry and remote sensing was started with a series of programs in Asian Conference on Remote Sensing (ACRS), an annual conference of remote sensing held in Asia. In 2007, at ACRS 2007 in Kuala Lumpur, Malaysia, the Student Session was held as a competition of presentations for introducing schools and institutes. That was a good opportunity to know outside of own 
schools and institutes. In addition, some presentations were so attractive using motion graphics that attending students were stimulated by the presentations. The Student Session was good as a first step of student activities to present own schools to students belonging to other schools. However, there were few interactive exchanges among students attended there.

In 2008, at ACRS 2008 in Colombo, Sri Lanka, the Student Session was held consisting of two parts. In the first part, professors and directors presented student programs. In the second part, students presented student activities in each country. After all of the presentations, the session was concluded with open discussion. Among the opinions from open discussions, the most considerable opinions were financial issues for students to participate in ACRS; and frequent exchange of information and opinions among students. Figrue 1 shows the Student Session.

In 2009, at ACRS 2009 in Beijing, China, technical sessions for undergraduate students and master students were separated to be held on the first day of ACRS 2009. The sessions were totally hosted by local students (Figure 2). After the student sessions, they had the Youth Party for cultural exchanges. The Student Session was also held with presentations of student programs and student activities. In 2010, at ACRS 2010 in Hanoi, Vietnam, the Student Session was held as a place to introduce student programs and student activities. During the presentations, establishment of communication platform for students were suggested.

After closing the ACRS 2010, ISPRS-SC Summer School was held at Vietnam Institute of Geodesy and Cartography during 610 November. The arrangement of the data and venue was very reasonable for students because students could join the summer school by just extending the stay for ACRS. As a result 54 students and youth from 13 countries joined the program including lecture on topographic mapping from high-resolution satellite sensors, change detection with focus on land cover / land use, agriculture and ecosystems, microwave remote sensing with focus on forestry applications, natural hazards and an excursion. The group photo in Vietnam is shown in figure 3.

In ACRS 2011 in Taipei, Taiwan, the student organizers have held two events for all student participants including "Student Session" and "Student Night". The scope of two events is to connect the knowledge and social network between Asian students. The detail information is as follow. The student session contained reports of student activities, student presentations, discussions, and announcements. The number of participants is about 50. In this time, there are 7 volunteers from 5 countries to introduce the student activities in their universities. The student night was organized by the local student organizers. The organizers have welcomed professors and registered students to attend this event, and the number of participants reaches 130. All participants are assigned into different groups with others who come from different countries. This event has successfully achieved to connect the social network for Asian students.

Directly after the ACRS 2011, ISPRS WG VI/5 and the Student Consortium (SC) hold the $7^{\text {th }}$ Summer School at the National Central University (NCU), Jhongli, Taoyuan, Taiwan during Oct. 8 - 12, 2011. The program included Image Quality Assessment, Agriculture Monitoring, UAV in Geomatics, Automated DSM Generation, Ocean Remote Sensing,
Terrestrial LIDAR, and a field trip. The number of participants was 48: 19 were from within Taiwan and 29 were from foreign countries. In addition to the lectures, there were two social events to establish the social network and experience the local culture. Figure 4 illustrates the participants of ISPRS-SC Summer School 2011 in Taiwan.

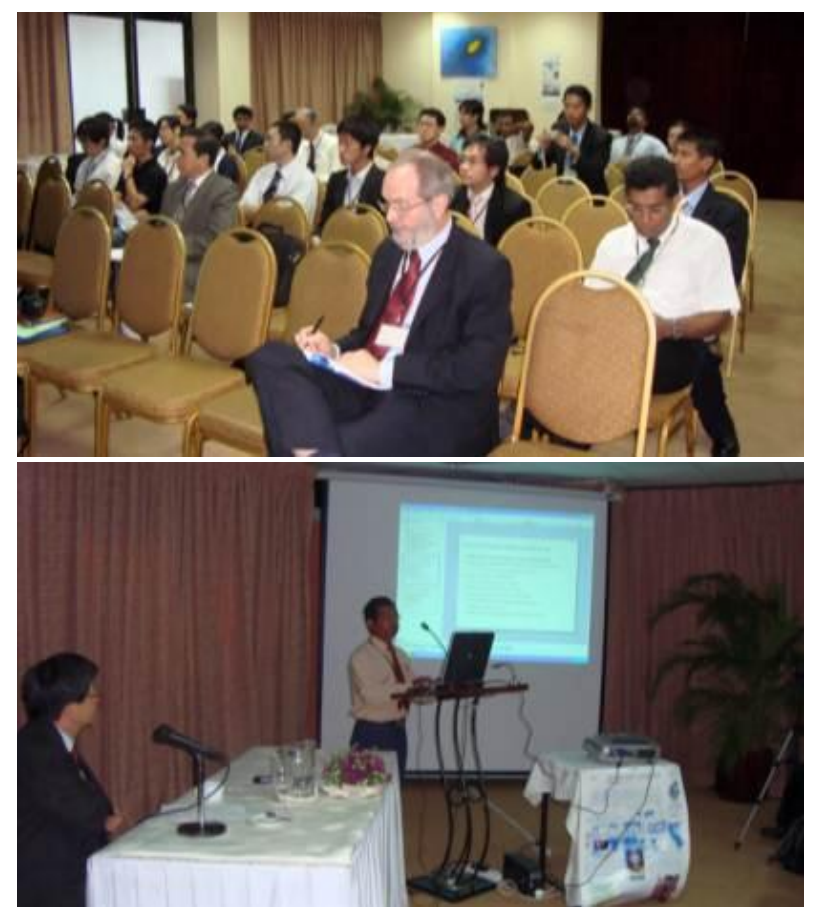

Figure 1. Student Session at the ACRS 2008

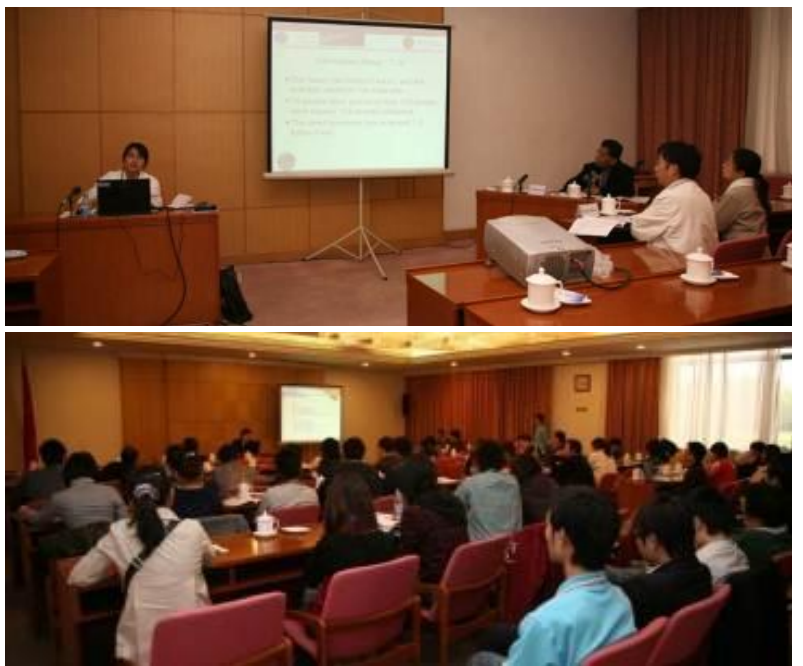

Figure 2. Technical sessions for students at the ACRS 2009 


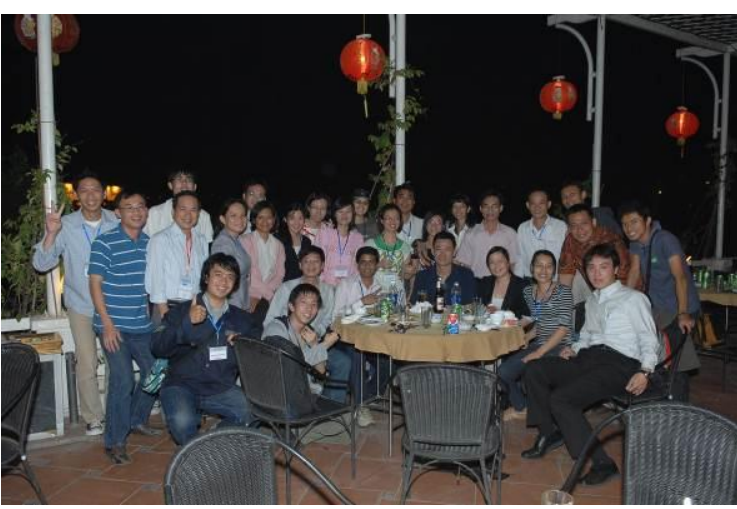

Figure 3. Group photo of ISPRS-SC Summer School 2010 in Vietnam

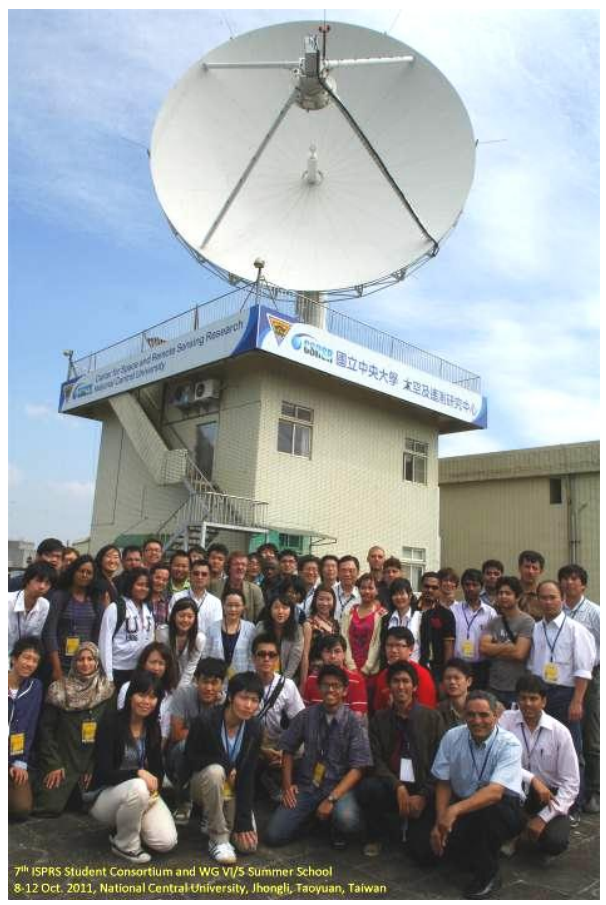

Figure 4. Group photo of ISPRS-SC Summer School 2011 in Taiwan

\section{PROPOSAL AND FUTURE PROSPECT}

Through five-year activities, we have identified issues for networking among Asian students and young scientists majoring remote sensing and photogrammetry. Firstly, we need to consider financial issues of students. To promote students attending conferences with financial support is an essential concern. In addition, arranging events directly after the annual conference is very effective for foreign students to save travel costs for the events as shown in the ISPRS-SC Summer School after the ACRS in 2010 and 2011. Therefore, coordination among relevant activities improves efficiencies of financial supports.

Secondly, we need to maintain networks built within the intensive opportunities during conferences and summer schools. There are many proposed possible solutions using social networking service such as Facebook, LinkedIn, Google Plus, etc. However, these services may be not available in some regions; we regarded that the fundamental solution may be to establish the "Student Chapter" under the national society to communicate all Asian students with a specialized website. This website should also contain the complete database with affiliations, emails, research areas, and materials of participants for the categorized networks. The organizers of "Student Chapter" should be the delegates from each member country. To fulfill this objective, we derived several tasks:

1. To extend the communication network from different countries based on the consideration of representative, General Secretary of AARS could invite all members to recommend one or two students to be local coordinators.

2. To organize the student group under AARS, the organizers from different countries may need their professors to support and assign works for the student organizations.

3. To establish AARS-SC (Student Consortium) statutes, the ISPRS-SC statutes could be a foundation and then modified by local coordinators.

4. The draft structure of AARS-SC may contain chair, co-chair, secretary, web responsible, publication responsible, national coordinators (contact people of each country), student members, and a supervisor (General Secretary of AARS). The basic financial support may come from AARS (Figure 5).

5. Construct the web page of AARS-SC for the communication and knowledge translation

By establishing the "Student Chapter", the existing network would be enhanced for circulating of information, keeping contacts among students and young scientists, and expanding the network.

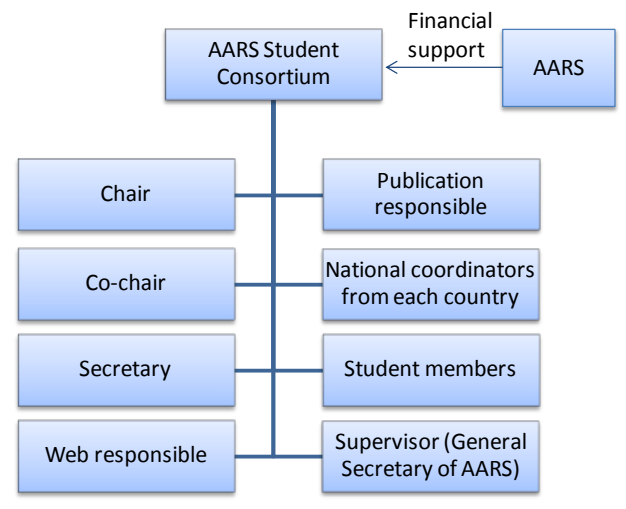

Figure 5. Proposed structure of the Student Chapter

\section{CONCLUSION}

This paper described a brief history of student activities associated to AARS. These are considerable progresses in networking Asian students of remote sensing and photogrammetry. Through the five-year activities, we identified two major issues: financial issues and establishing a "Student Chapter". For financial issues, not only financial support, saving travel cost by holding events together is effective to promote student engagement. For the second issue, we concluded that establishing "Student Chapter" for sustainable networks with support of AARS and ACRS. By realizing such a sustainable network, friendships of students and young scientists would be grown to innovations for public societies. 
International Archives of the Photogrammetry, Remote Sensing and Spatial Information Sciences, Volume XXXIX-B6, 2012 XXII ISPRS Congress, 25 August - 01 September 2012, Melbourne, Australia

\section{ACKNOLEDGEMENT}

The student activities have been fully supported by AARS, ISPRS, relevant sponsors, and volunteer students. We sincerely thank to continuous supports by those. 